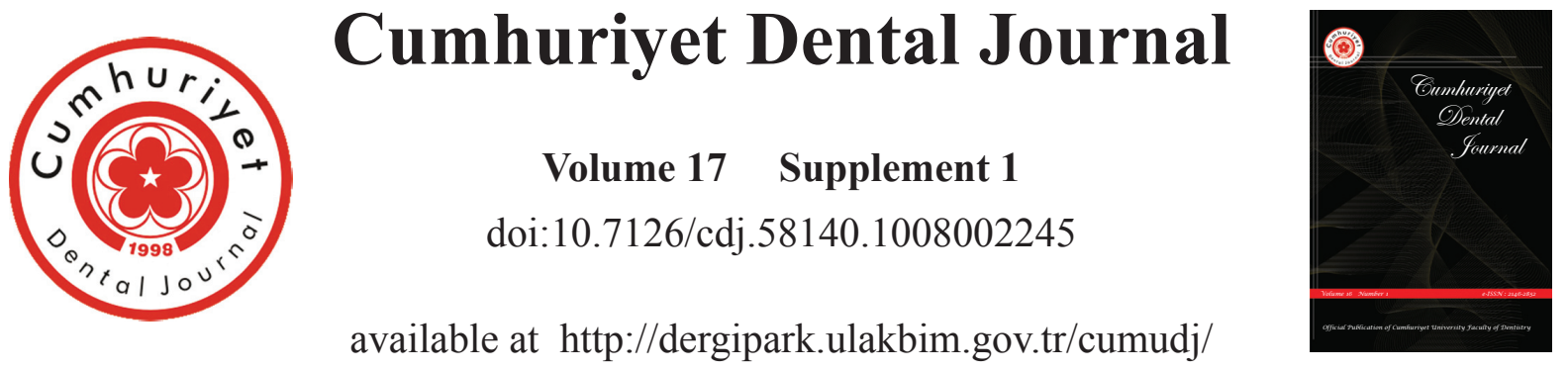

CASE REPORT

\title{
Rehabilitation of a large radicular cyst of the mandible without using any bone substitutes: case report
}

\author{
Ahmet Ferhat Misir, DDS, PhD, ${ }^{a}$ M. Birol Ugur, $M D,{ }^{b}$ Nilüfer Onak Kandemir, $M D^{c}$ \\ ${ }^{a}$ Bülent Ecevit University, Faculty of Dentistry, Department of Oral and Maxillofacial Surgery, Zonguldak, Tukey \\ ${ }^{b}$ Bülent Ecevit University, Faculty of Medicine, Department of Ear, Nose and Throat, Zonguldak, Tukey \\ 'Bülent Ecevit University, Faculty of Medicine, Department of Pathology, Zonguldak, Tukey
}

\section{A R T I C L E I N F O}

Article history:

Received 15 July 2013

Accepted 09 October 2013

Keywords:

Radicular cyst

Mandible

Surgical enucleation

\begin{abstract}
A B S T R A C T
The radicular cyst variously known as periapical, apical periodontal, dentoalveolar or rootend cyst is an inflammatory jaw cyst at the apices of teeth with infected and necrotic pulps. A radicular cyst arises from the epithelial residues in the periodontal ligament as a result of inflammation, usually following death of the pulp. Radicular cysts are the most common odontogenic cystic lesions of inflammatory origin and are managed either by surgical enucleation or by marsupialization. We illustrate the possibility of complete healing of a cystic periapical lesion of huge proportion in permanent dentition of a 58 year-old male patient under general anesthesia with conservation of vital structures and without using any bone substitute.
\end{abstract}

\section{INTRODUCTION}

Radicular cysts are the most common inflammatorycystsarisingfromtheepithelial residues in the periodontal ligament as a result of periapical periodontitis following necrosis of the pulp, remains asymptomatic and left unnoticed until detected during routine periapical radiography.

These cysts comprise about $52 \%$ to $68 \%$ of all the cysts affecting the human jaw. ${ }^{1}$ Their incidence is highest in third and fourth decade of life with male predominance. ${ }^{2}$ Anatomically the periapical cysts occur in all tooth-bearing sites of the jaw but are more frequent in the maxillary than the mandibular region. ${ }^{1,3}$

Radicular cysts can heal spontaneously after endodontic treatment or extraction. However, some authors propose that suspected radicular cysts must be totally enucleated surgically to remove all epithelial remnants. ${ }^{4,5}$

Corresponding author at: Ahmet Ferhat MISIR, Bülent Ecevit Universitesi, Dishekimligi Fakultesi, Agiz Dis ve Cene Cerrahisi Anabilim Dali, 67600 Kozlu, Zonguldak Turkey, Phone: 0090 (372) 2613412, Fax: 0090 (372) 2613403. E-mail: afmisir@karaelmas.edu.tr 


\section{CASE REPORT}

A 58-year-old male with no past medical history was referred by his general dentist to the Department of Oral and Maxillofacial Surgery of Bülent Ecevit University for the large, well-defined asymtomatic radiolusent lesion located in the right mandibular premolar-molar region during routine dental examination. On our extraoral examination there was no swelling and no pain.

Upon clinical examination, palpation of the vestibular sulcus revealed fluctuation, while at places egg-shell crackling could be elicited. The lower right canine and the premolars did not respond to thermal and electrical vitality tests and were not tender to percusion. No history trauma was recorded and all other teeth in the lower anterior area were vital. Radiographic examination revealed that radiolucent lesion extended laterally from the root of the lower right canine to the entire corpus of the mandible, as though the entire marrow of the body of the bone had been replaced by an extensive cyst (Figure 1,2). Aspiration of the cystic cavity with a no. 18 gauge needle yielded a straw colored fluid.

A diagnosis of radicular cyst was made and the patient was sent for endodontic treatment of lower right canine and premolars to restorative clinic of Bülent Ecevit University.

After endodontic treatment, the cyst was totally enucleated and the lower

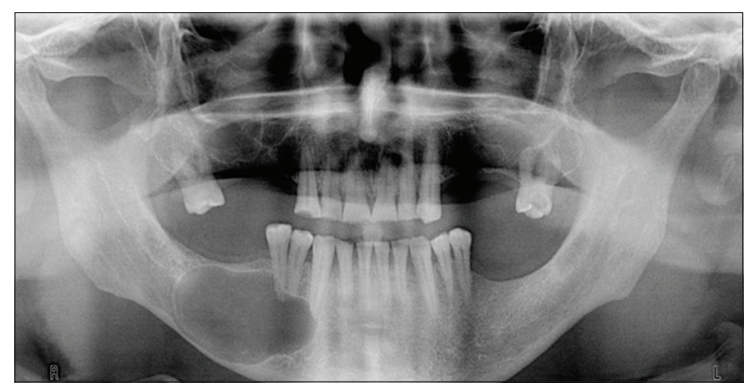

Figure 1. Preoperative ortopantomograph showing a large cystic lesion located in the right mandibular corpus. canine and premolars roots were resected with an intraoral approach under general anesthesia. The inferior alveolar nevre sheath was visualized and carefully protected during the surgical procedure (Figure 2). A miniplate and screw set for internal fixation and reconstruction was ready during the operation in case of any pathological fracture of the mandible. The excised tissue was sent for histopathologic examination. The findings in the report revealed to cyst epithelial (Figure 3).

The patient was discharged, having given the carer postoperative instructions for the administration of postoperative medication. Communication was made with the patient the day following the surgery;

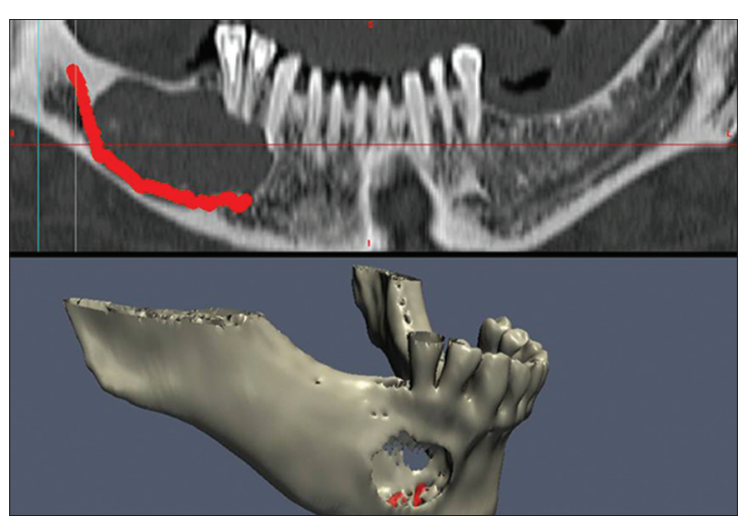

Figure 2. Preoperative computerized tomographic view showing the cyst in the close relation with the inferior alveolar nevre.

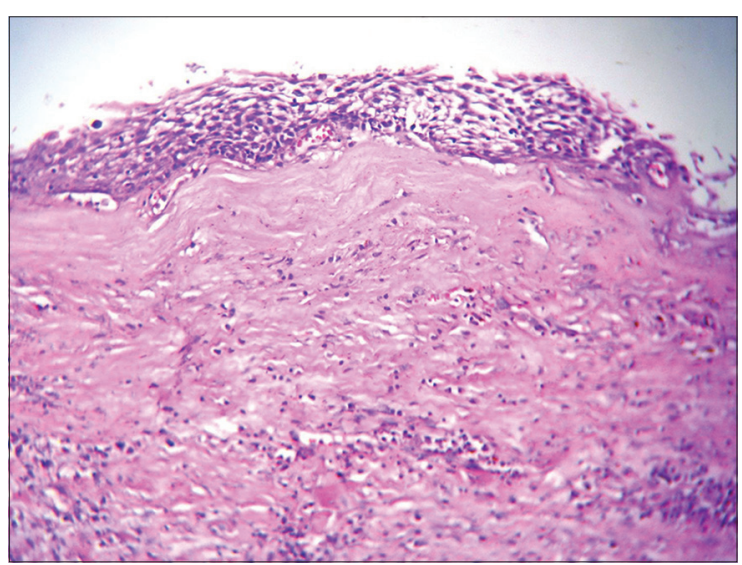

Figure 3. Photomicrograph showing cystic wall with stratified squamous epithelium (H\&E, x200). 
other than visible bruising he had no discomfort and he reported no paresthesia. The patient was seen postoperatively at the intervals of 7 days, 21 days, 3 months, and 6 months. Residual sutures were removed after 21 days.

After 1 year the patient was asymtomatic and the bone healing was satisfactory (Figure 4,5). Removable and fixed prosthetic rehabilitation were made since the patient rejected the dental implant retained prostetic treatment (Figure 6). Informed consent form was taken from the patient according to use patient details fort his case report.

\section{DISCUSSION}

The management of large cystic lesions is still debatable, with some authors claiming that true cysts can only be successfully treated by surgical means however, current treatment concepts claim that

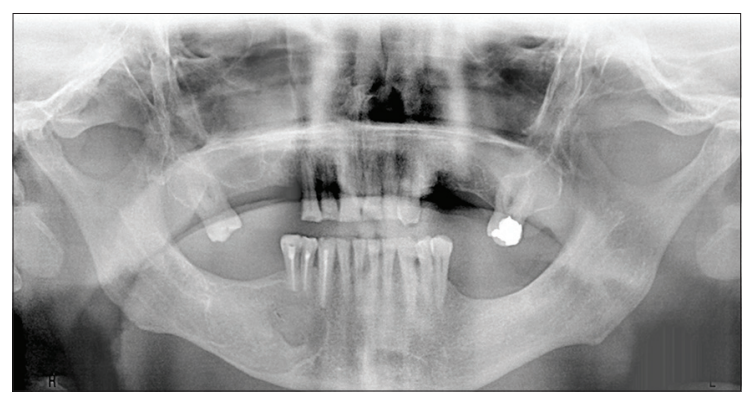

Figure 4. Ortopantomograph showing the bone regeneration after 18 months postoperatively.

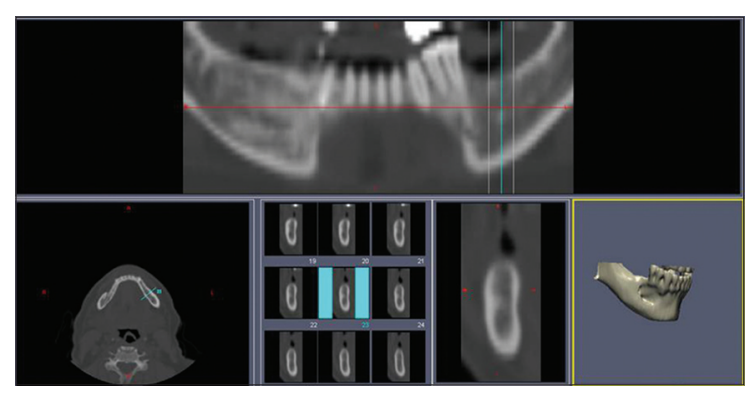

Figure 5. Postoperative computerized tomographic view showing enough bone healing for prothetic rehabilitation. a large number of cysts will heal after non-surgical root canal treatment. But, root canal treatment may not always be possible or guarantee the good results in large periapical lesions and non-surgical retreatment or surgery may be required in these cases. ${ }^{3,6}$ In this report, due to the present case was large, enucleation was performed.

Especially large periapical lesions of odontogenic origin are found in the maxilla where the bone is spongy. Because of the bone consistency, it is easier for the lesion to occupy bony space and expand. Lesions expanding the entire sinus and even the floor of the nasal cavity were reported. ${ }^{7}$ However, the extensive radicular cyst seen in this case report was found in the corpus of mandible.

Radicular cysts cause slowly progressive painless swellings. There are no symptoms until they become quite large. If infected, the swelling becomes painful and may rapidly increase in size, partly due to inflammatory edema. ${ }^{8}$ Adjacent teeth may be tilted or displaced a little or occasionally become slightly mobile. In this report, teeth associated with lesions were not mobile and affected teeth were nonvital.

Periapical cysts are usually asymptomatic and are often discovered incidentally during routine dental radiographic examination. The radiolucency associated

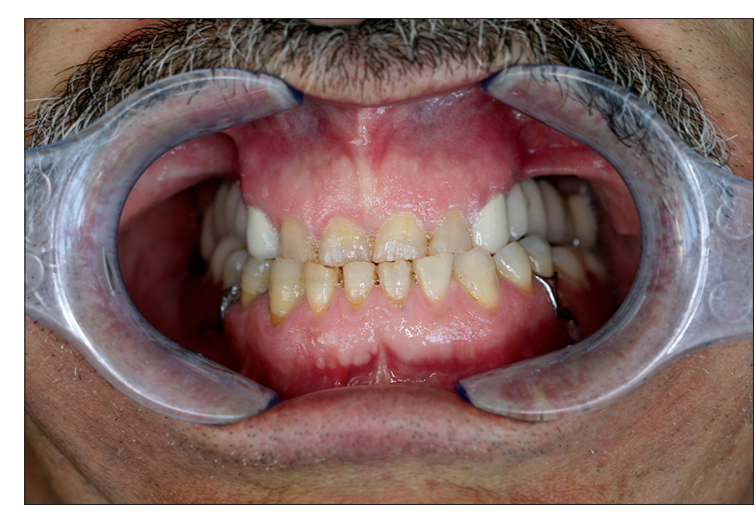

Figure 6. Clinical view after prosthetic rehabilitation. 
with a periapical cyst is generally round to ovoid, with a narrow, opaque margin that is contiguous with the lamina dura of the involved tooth. ${ }^{8}$ The borders of the lesion are generally well defined and sclerotic magrin that is contiguous with the lamina dura of the affected tooth.

The surgery was undertaken under general anesthesia with enucleation and curettage for these reasons in this case and any bone graft were used. Several studies have reported safe and regular bone healing after enucleation and simple closure of jaw cysts without using bone grafts even in cases of large defects. ${ }^{9-12}$ The complication rate for cyst enucleation, primary closure and perioperative antibiotic treatment seems to be less than $5 \%$, even in defects measuring far more than $3 \mathrm{~cm}^{4,12-14}$ Despite the extension of the lesion, complications such as permanent bony defects or pathologic fractures did not occur in the present case.

Karamanis et $\mathrm{al}^{14}$ reported that the placement of small quantity of an osseoconductive bone substitute in a cyst defect after marsupialization is advantageous than autografting procedures. On the other hand, Cakarer et $\mathrm{al}^{15}$ reported that the resolution of the large defect of a dentigerous cyst, beforeimplant insertion, is achieved without resorting to bone grafting procedures. The result of the present case is consistent with the similar cases suggesting that the large cyst defects can be resolved without using graft materials.

In conclusion, a radicular cyst is a common condition found in the oral cavity. However, it usually goes unnoticed and rarely the size exceeds large in dimension. This case illustrates an extensive radicular cyst, located in the mandibular corpus, surgical treatment with enucleation and without using any bone substitutes or reconstructive technique. The patient was monitored 1 year postoperatively without any complications and prosthetic rehabilitation was made.

\section{REFERENCES}

1. Nair PN. Review New perspectives on radicular cysts: Do they heal? Int Endod J. 1998;31:155-160.

2. Shear M. Cysts of the Oral Regions. $3^{\text {rd }}$ ed. Wright. Oxford, 1992:137-62.

3. Rees JS. Conservative management of a large maxillary cyst. Int Endod J. 1997;30:64-67.

4. Walton RE. The residual radicular cyst: Does it exist? Oral Surg Oral Med Oral Pathol Oral Radiol Endod. 1996;82:471.

5. Yilmaz HG, Bayindir H. Lateral periodontal kist görünümlü radiküler kistin ve eksternal kök rezorpsiyonunun cerrahi ve endodontik tedavisi. Cumhuriyet Dent J 2012;15:48-54.

6. Delantoni A, Papademitriou P. An unusually large asymptomatic periapical lesion that presented as a random finding on a panoramic radiograph. Oral Surg Oral Med Oral Pathol Oral Radiol Endod. 2007:104;e62-e65.

7. Gibson GM, Pandolfi PJ, Luzader JO. Case report: A large radicular cyst involving the entire maxillary sinus. Gen Dent. 2002:50;80-81.

8. Regezi JA, Sciubba JJ, Jordan RCK. Oral Pathology Clinical Pathologic Correlations. $4^{\text {th }}$ ed. Saunders. St. Louis Missouri, 2003:241-244.

9. Chiapasco M, Rossi A, Motta JJ, Crescentini M. Spontaneous bone regeneration after enucleation of large mandibular cysts: A radiographic computed analysis of 27 consecutive cases. J Oral Maxillofac Surg. 2000;58:942.

10. Ihan Hren N, Miljavec M:Spontaneous bone healing of the large bone defects in the mandible. Int J Oral Maxillofac Surg. 2008;37:1111-1116.

11. Iatrou I, Theologie-Lygidakis $\mathrm{N}$, Leventis M. Intraosseous cystic lesions of the jaws in children: 
a retrospective analysis of 47 consecutive cases. Oral Surg Oral Med Oral Pathol Oral Radiol Endod. 2009;107:485-492.

12. Pappalardo $S$, Coronella $M$, Lanza ML, Rabbito V, Foti PV, Mauro LA, Palmucci S, Ettorre GC. Multidetector CT Dentascan evaluation of bone regeneration obtained with deproteinised bovine graft in residual cavity after mandibular cyst enucleation. Radiol Med. 2013;118:523-533.
13. Misir AF, Türer A, Bulut E, Sümer $M$, Karagöz F. Rehabilitation of benign pathological condition by dental implants. JDI. 2012;2:127-130.

14. Karamanis $S$, Kitharas $T$, Tsoukalas D, Parissis N. Implant placement after marsupialization of a dentigerous cyst. J Oral Implantology 2006;32:313-316.

15. Cakarer S, Selvi F, Isler SC, Keskin C. Decompression, enucleation, and implant placement in the management of a large dentigerous cyst. J Craniofac Surg. 2011;22:922-924.

How to cite this article: Ahmet Ferhat Misir, M. Birol Ugur, Nilüfer Onak Kandemir. Rehabilitation of a large radicular cyst of the mandible without using any bone substitutes : case report. Cumhuriyet Dent J 2014;17(Supp 1):53-57. 